Pacific Journal of Mathematics

EXTENDING BOUNDED HOLOMORPHIC FUNCTIONS FROM 


\section{EXTENDING BOUNDED HOLOMORPHIC FUNCTIONS FROM CERTAIN SUBVARIETIES OF A POLYDISC}

\section{Herbert AleXANDER}

Let $E$ be a subvariety of the unit polydisc

$$
U^{N}=\left\{\left(z_{1}, \cdots, z_{N}\right) \in C^{N}:\left|z_{i}\right|<1,1 \leqq i \leqq N\right\}
$$

such that $E$ is the zero set of a holomorphic function $f$ on $U^{N}$, i.e., $E=Z(f)$ where $Z(f)=\left\{z \in U^{N}: f(z)=0\right\}$. This amounts to saying that $E$ is a subvariety of pure dimension $N-1$. In [2] Walter Rudin proved that if $E$ is bounded away from the torus $T^{N}=\left\{\left(z_{1}, \cdots, z_{N}\right) \in C^{N}:\left|z_{i}\right|=1,1 \leqq i \leqq N\right\}$, then there is a bounded holomorphic function $F$ on $U^{N}$ such that $E=Z(F)$. Call such a subvariety $E$, that is, a pure $N-1$ dimensional subvariety of $U^{N}$ bounded from $T^{N}$, a $R$ udin variety. We are interested in the following question: When is it possible to extend every bounded holomorphic function on a Rudin variety $E$ to one on $U^{N}$ ? Examples show this is not always possible. We will say that a pure $N-1$ dimensional subvariety $E$ of $U^{N}$ is a special Rudin variety if there exists an annular domain $Q^{N}=\left\{\left(z_{1}, \cdots, z_{N}\right) \in C^{N}: r<\left|z_{i}\right|<1,1 \leqq i \leqq N\right\}$ for some $r(0<r<1)$ and a $\delta>0$ such that

(i) $E \cap Q^{N}=\varnothing$ and

(ii) if $1 \leqq k \leqq N$ and $\left(z^{\prime}, \alpha, z^{\prime \prime}\right) \in\left(Q^{k-1} \times U \times Q^{N-k}\right) \cap E$ and $\left(z^{\prime}, \beta, z^{\prime \prime}\right) \in\left(Q^{k-1} \times U \times Q^{N-k}\right) \cap E$ and $\alpha \neq \beta$, then $|\alpha-\beta| \geqq \delta$. Obviously (i) implies that a special Rudin variety is a Rudin variety. We have the

Theorem. If $E$ is a special Rudin variety in $U^{N}$, then there exists a bounded linear transformation $T: H^{\infty}(E) \rightarrow H^{\infty}\left(U^{N}\right)$ (where $H^{\infty}$ is the corresponding Banach space of bounded holomorphic functions under sup norm) which extends each bounded holomorphic function on $E$ to one on $U^{N}$.

REMARK. The proof of the theorem is a modification of the proof in [2] of Rudin's theorem: the changes reflecting the fact that we are dealing with an additive problem while Rudin's was of a multiplicative nature. I am further indebted to Professor Rudin for some comments (on a preliminary version of this paper) which led to improvement in the hypothesis of the theorem.

The following lemma is well-known and easy to prove.

Lemma 1. If $0<r<1$ and $Q=\{\lambda \in C: r<|\lambda|<1\}$ and

$$
h(\lambda)=\sum_{-\infty}^{\infty} a_{n} \lambda^{n}, h_{1}(\lambda)=\sum_{-\infty}^{-1} a_{n} \lambda^{n}
$$


for $\lambda \in Q$, then

$$
\left\|h_{1}\right\|_{Q} \leqq K\|h\|_{Q}
$$

where $K(>1)$ is a constant depending only on $r$.

If $h$ is holomorphic on $Q^{N}=\left\{\left(z_{1}, \cdots, z_{N}\right): r<\left|z_{i}\right|<1,1 \leqq i \leqq N\right\}$ then $h$ has a Laurent expansion

$$
h\left(z_{1}, z_{2}, \cdots, z_{N}\right)=\sum a\left(n_{1}, n_{2}, \cdots, n_{N}\right) z_{1}{ }^{n_{1}} z_{2}{ }^{n_{2}} \cdots z_{N}{ }^{n_{N}} .
$$

Following [2], we define $\pi_{j} h, 1 \leqq j \leqq N$, to be the holomorphic function on $Q^{N}$ whose Laurent series is obtained by deleting in (1) all terms in which $n_{j} \geqq 0$. Lemma 1 implies

\section{Lemma 2. $\left\|\pi_{j} h\right\|_{Q^{N}} \leqq K\|h\|_{Q^{N}}$.}

Proof of the theorem. Since $E$ is a subvariety of $U^{N}$ of pure dimension $N-1$, there exists by [1, p. 251] a function $f$ holomorphic on $U^{N}$ such that at each point of $U^{N}$ the germ of $f$ generates the ideal of germs of holomorphic functions which vanish on the germ of $E$ at the given point. In particular, $E=Z(f)$. We will show that $\partial f / \partial z_{k} \neq 0$ on $\left(Q^{k-1} \times U \times Q^{N-k}\right) \cap E$ for $1 \leqq k \leqq N$. We give the proof for $k=1$, the other cases are identical. Let $\left(\alpha, \alpha^{\prime}\right) \in\left(U \times Q^{N-1}\right) \cap E$. Now $f$ is regular in the first coordinate [1, p. 13] at $\left(\alpha, \alpha^{\prime}\right)$ since otherwise $f\left(\zeta, \alpha^{\prime}\right)$ vanishes in a neighborhood of $\alpha$ and hence for $|\zeta|<1$ and so $E=Z(f) \supseteqq\left\{\left(\zeta, \alpha^{\prime}\right):|\zeta|<1\right\}$, contradicting (i) in the definition of a special Rudin variety. Thus we can apply the Weierstrass preparation theorem and write in some neighborhood of $\left(\alpha, \alpha^{\prime}\right), f=\Omega p$ where $\Omega$ is invertible and $p$ is a Weierstrass polynomial. Factor $p$ into primes: $p=p_{1}^{e_{1}} \cdots p_{t}^{t_{t}}$ where $p$ and the $p_{i}$ 's are of the form

$$
(\zeta-\alpha)^{n}+a_{n-1}\left(\zeta^{\prime}\right)(\zeta-\alpha)^{n-1}+\cdots+a_{0}\left(\zeta^{\prime}\right)
$$

for $\left(\zeta, \zeta^{\prime}\right)$ near $\left(\alpha, \alpha^{\prime}\right)$ with $a_{j}\left(\alpha^{\prime}\right)=0$. Now the degree of each $p_{i}$ must be equal to 1 since otherwise there would exist $\zeta_{n}^{\prime} \rightarrow \alpha^{\prime}$ with $\zeta_{n}^{\prime}$ off the discriminant locus of some $p_{i}$ and so there would exist $\alpha_{n} \neq \beta_{n}$ near $\alpha$ with $p_{i}\left(\alpha_{n}, \zeta_{n}^{\prime}\right)=0=p_{i}\left(\beta_{n}, \zeta_{n}^{\prime}\right)$ and thus $\left(\alpha_{n}, \zeta_{n}^{\prime}\right)$ and $\left(\beta_{n}, \zeta_{n}^{\prime}\right)$ are in $\left(U \times Q^{N-1}\right) \cap E$, but $\zeta_{n}^{\prime} \rightarrow \alpha^{\prime}$ implies $\alpha_{n} \rightarrow \alpha$ and $\beta_{n} \rightarrow \alpha$ and so $\left|\alpha_{n}-\beta_{n}\right| \rightarrow 0$, contradicting (ii). A similar argument also using (ii) shows that there cannot be more than one $p_{i}$ and so $f=\Omega p_{1}^{e_{1}}$ near $\left(\alpha, \alpha^{\prime}\right)$. Finally, since the germ of $f$ generates the ideal of $E$ at $\left(\alpha, \alpha^{\prime}\right), e_{1}$ must be equal to 1 . Thus $f\left(\zeta, \zeta^{\prime}\right)=\Omega\left(\zeta, \zeta^{\prime}\right)\left(\zeta-\alpha+a_{0}\left(\zeta^{\prime}\right)\right)$ and $\partial f / \partial \zeta\left(\alpha, \alpha^{\prime}\right)=\Omega\left(\alpha, \alpha^{\prime}\right) \neq 0$ as required.

Now by Theorem 1 of [2] applied to $E=Z(f)$ there is a bounded holomorphic function $F$ on $U^{N}$ such that $E=Z(F)$. Examination of the 
construction in [2] shows that $1 / F$ is bounded on $Q^{N}$ since $F=f_{1} e^{g-g_{1}}$ on $Q^{N}$ and $1 / f_{1}$ and $\left|\operatorname{Re}\left(g-g_{1}\right)\right|$ are bounded on $Q^{N}$. We will show that there is an $\varepsilon>0$ such that $\left|\partial F / \partial z_{k}\right|>\varepsilon$ on $\left(Q^{k-1} \times U \times Q^{N-k}\right) \cap E$ for $1 \leqq k \leqq N$. We do this for $k=1$, the finitely many other cases are identical. From [2], $F=f e^{g}$ for some $g$ and so $\partial f / \partial z_{1} \neq 0$ on $\left(U \times Q^{N-1}\right) \cap E$ implies $\partial F / \partial z_{1} \neq 0$ there. Now for $z^{\prime} \in Q^{N-1}$

$$
z^{\prime} \rightarrow \frac{1}{2 \pi i} \int_{|\zeta|=r} \frac{\partial F / \partial z_{1}\left(\zeta, z^{\prime}\right)}{F\left(\zeta, z^{\prime}\right)} d \zeta
$$

is a continuous integer-valued function and so is a constant $m_{1}$ giving the number of zeros for $F\left(\cdot, z^{\prime}\right)$ in $U$. Since these zeros are the points of $\left(U \times Q^{N-1}\right) \cap E$ and $\partial F / \partial z_{1} \neq 0$ there, it follows that the $m_{1}$ zeros $\alpha_{1}\left(z^{\prime}\right), \cdots, \alpha_{m_{1}}\left(z^{\prime}\right)$ are distinct simple zeros. By (ii) then, $\left|\alpha_{i}\left(z^{\prime}\right)-\alpha_{j}\left(z^{\prime}\right)\right| \geqq \delta$ for $i \neq j$. Write $F\left(\cdot, z^{\prime}\right)=B H$, where $B$ is the Blaschke product with zeros at $\alpha_{1}\left(z^{\prime}\right), \cdots, \alpha_{m_{1}}\left(z^{\prime}\right)$. Now since $1 / F$ is bounded on $Q^{N} 1 / H$ is bounded on $U$. But on $E, \partial F / \partial z_{1}=\partial B / \partial z_{1} \cdot H$ and since

$$
\left|\alpha_{i}\left(z^{\prime}\right)-\alpha_{j}\left(z^{\prime}\right)\right| \geqq \delta, \partial B / \partial z_{1}
$$

is bounded from zero on $E$ by some constant depending on $\delta$, and as $H$ is also bounded from zero independently of $z^{\prime}$, it follows that $\partial F / \partial z_{1}$ is bounded from zero on $\left(U \times Q^{N-1}\right) \cap E$.

Let $d=\operatorname{dist}\left(E, Q^{N}\right)$ which we may assume is positive by increasing $r$ if need be. Let $g$ be a bounded holomorphic function on $E$. We shall extend $g$ to a bounded function on $U^{N}$. By the general OkaCartan theory [1], there is a holomorphic extension $G$ of $g$ to $U^{N} ; G$ need not be bounded. Since $F \neq 0$ on $Q^{N}$, we may define a function $h_{1}$ on $U \times Q^{N-1}$ as follows: Let $\left(z_{1}, z^{\prime}\right) \in U \times Q^{N-1}$. Choose a circle $\Gamma$ about 0 lying in $Q$ and enclosing $z_{1}$ with positive orientation and set

$$
h_{1}\left(z_{1}, z^{\prime}\right)=\frac{1}{2 \pi i} \int_{\Gamma} \frac{G\left(\zeta, z^{\prime}\right) / F\left(\zeta, z^{\prime}\right)}{\zeta-z_{1}} d \zeta .
$$

$h_{1}$ is clearly independent of the choice of $\Gamma$ and holomorphic on $U \times Q^{N-1}$. We claim that $G / F-h_{1}$ is bounded on $Q^{N}$. Let $\left(z_{1}, z^{\prime}\right) \in Q^{N}$ where $z_{1} \in Q$, $z^{\prime} \in Q^{N-1}$. Let $\Gamma_{1}, \Gamma_{2}, \cdots, \Gamma_{m_{1}}$ be small circles about $\alpha_{1}\left(z^{\prime}\right), \cdots, \alpha_{m_{1}}\left(z^{\prime}\right)$, the zeros of $F\left(\cdot, z^{\prime}\right)$. Then the Cauchy integral formula reads

$$
(G / F)\left(z_{1}, z^{\prime}\right)=\frac{1}{2 \pi i} \int_{\Gamma-\Gamma_{1}-\cdots \Gamma_{m_{1}}} \frac{G\left(\zeta, z^{\prime}\right) / F\left(\zeta, z^{\prime}\right)}{\zeta-z_{1}} d \zeta .
$$

Therefore

$$
\left(G / F-h_{1}\right)\left(z_{1}, z^{\prime}\right)=-\sum_{1}^{m_{1}} \frac{1}{2 \pi i} \int_{\Gamma_{k}} \frac{G\left(\zeta, z^{\prime}\right) / F\left(\zeta, z^{\prime}\right)}{\zeta-z_{1}} d \zeta .
$$

Clearly for $r_{k}=$ radius of $\Gamma_{k}$, 


$$
\begin{aligned}
& \frac{1}{2 \pi i} \int_{\Gamma_{k}} \frac{G\left(\zeta, z^{\prime}\right) / F\left(\zeta, z^{\prime}\right)}{\zeta-z_{1}} d \zeta \\
= & \frac{1}{2 \pi i} \int_{\left|\zeta-\alpha_{k}\left(z^{\prime}\right)\right|=r_{k}} \frac{G\left(\zeta, z^{\prime}\right)}{\zeta-z_{1}} \frac{\zeta-\alpha_{k}\left(z^{\prime}\right)}{F\left(\zeta, z^{\prime}\right)-F\left(\alpha_{k}\left(z^{\prime}\right), z^{\prime}\right)} \frac{d \zeta}{\zeta-\alpha_{k}\left(z^{\prime}\right)} \\
& \rightarrow \frac{g\left(\alpha_{k}\left(z^{\prime}\right), z^{\prime}\right)}{\left(\alpha_{k}\left(z^{\prime}\right)-z_{1}\right) \frac{\partial F}{\partial \zeta_{1}}\left(\alpha_{k}\left(z^{\prime}\right), z^{\prime}\right)}
\end{aligned}
$$

So letting the radii of the $\Gamma_{k}$ go to zero we get

$$
\left(G / F-h_{1}\right)\left(z_{1}, z^{\prime}\right)=-\sum_{k=1}^{m_{1}} \frac{g\left(\alpha_{k}\left(z^{\prime}\right), z^{\prime}\right)}{\left(\alpha_{k}\left(z^{\prime}\right)-z_{1}\right) \frac{\partial F}{\partial \zeta_{1}}\left(\alpha_{k}\left(z^{\prime}\right), z^{\prime}\right)} .
$$

Since $\left(\alpha_{k}\left(z^{\prime}\right), z^{\prime}\right) \in\left(U \times Q^{N-1}\right) \cap E$, recalling the significance of $d$ and $\varepsilon$ we get

$$
\left\|G / F-h_{1}\right\|_{Q^{N}} \leqq \frac{m_{1}\|g\|_{E}}{d \varepsilon}
$$

In the same way for each $i, 1<i \leqq N$ we have an integer $m_{i}$ and a function $h_{i}$ holomorphic on $Q^{i-1} \times U \times Q^{N-i}$ such that

$$
\left\|G / F-h_{i}\right\|_{Q^{N}} \leqq \frac{m_{i}\|g\|_{E}}{d \varepsilon} .
$$

Now let $m=\max \left\{m_{i}: 1 \leqq i \leqq N\right\}$ and let $A=m / d \varepsilon$. Subtracting in the above, we get $\left\|h_{1}-h_{i}\right\|_{Q^{N}} \leqq 2 A\|g\|_{E}$. Now following [2] closely, set $h=\left(1-\pi_{1}\right)\left(1-\pi_{2}\right) \cdots\left(1-\pi_{N}\right) h_{1}$. Since $\pi_{i} h=0, h$ extends (uniquely) to a holomorphic function on $U^{N}$. Since $h_{j}$ is holomorphic on

$$
Q^{3-1} \times U \times Q^{N-j}, \pi_{j} h_{j}=0
$$

and so $\pi_{j} h_{1}=\pi_{j}\left(h_{1}-h_{j}\right)$ and therefore by Lemma 2 ,

$$
\left\|\pi_{j} h_{1}\right\|_{Q^{N}}=\| \pi_{j}\left(h_{1}-h_{j}\left\|_{Q^{N}} \leqq K\right\| h_{1}-h_{j}\left\|_{Q^{N}} \leqq 2 K A\right\| g \|_{E} \cdot\right.
$$

Now, since $h-h_{1}=-\sum \pi_{i} h_{1}+\sum \pi_{i} \pi_{j} h_{1}-+\cdots$ and since we get by induction and by use of Lemma 2 that $\left\|\pi_{i_{1}} \pi_{i_{2}} \cdots \pi_{i_{S}} h_{1}\right\|_{Q^{N}} \leqq 2 K^{S} A\|g\|_{E}$, it follows that $\left\|h-h_{1}\right\|_{Q^{N}} \leqq B A\|g\|_{E}$ where $B$ depends only on $K$. Now consider $\bar{G}=G-F h . \quad \bar{G}$ is holomorphic on $U^{N}$ and extends $g$ since $G$ does. On $Q^{N}, \bar{G}=F\left(G / F-h_{1}\right)+F\left(h_{1}-h\right)$. Therefore $\|\bar{G}\|_{Q^{N}} \leqq\|F\|_{U^{N}} A\|g\|_{E}+\|F\|_{U^{N}} B A\|g\|_{E}$. Thus $\bar{G}$ is bounded on $U^{N}$ and $\|\bar{G}\|_{U^{N}} \leqq \gamma\|g\|_{E}$ where $\gamma=A(1+B)\|F\|_{U^{N}}$ is independent of $g$.

Next we show that $\bar{G}$ does not depend on the choice of $G$ made at the beginning of the construction. Suppose $\widetilde{G}$ were another (not necessarily bounded) extension of $g$ to $U^{N}$. As above we get 


$$
\tilde{h}_{1}=\frac{1}{2 \pi i} \int_{\Gamma} \frac{\widetilde{G} / F}{\zeta-z_{1}} d \zeta
$$

But then on $U \times Q^{N-1}$

$$
h_{1}-\widetilde{h}_{1}=\frac{1}{2 \pi i} \int \frac{(G-\widetilde{G}) / F}{\zeta-z_{1}} d \zeta .
$$

Since for $z^{\prime} \in Q^{N-1},(G-\widetilde{G})\left(\cdot, z^{\prime}\right)$ vanishes at $\alpha_{1}\left(z^{\prime}\right), \cdots, \alpha_{m_{1}}\left(z^{\prime}\right)$ and since $F\left(\cdot, z^{\prime}\right)$ has simple zeros and only at these points, $(G-\widetilde{G}) / F\left(\cdot, z^{\prime}\right)$ is holomorphic on $U$ and the right hand side of (2) equals $(G-\widetilde{G}) / F$ and so on $U \times Q^{N-1}$

$$
h_{1}-\widetilde{h}_{1}=(G-\widetilde{G}) / F .
$$

Since the left hand side of (3) is holomorphic on $U \times Q^{N-1}$, so is the right and consequently $(G-\widetilde{G}) / F=\left(1-\pi_{1}\right)((G-\widetilde{G}) / F)$ on $Q^{N}$. In the same way we see that for each $j,(G-\widetilde{G}) / F=\left(1-\pi_{j}\right)((G-\widetilde{G}) / F)$ on $Q^{N}$. Therefore on $Q^{N}$ we have

$$
(G-\widetilde{G}) / F=\prod_{j=1}^{N}\left(1-\pi_{j}\right)(G-\widetilde{G}) / F=\prod_{j=1}^{N}\left(1-\pi_{j}\right)\left(h_{1}-\widetilde{h}_{1}\right)=h-\tilde{h} .
$$

Thus $G-F h=\widetilde{G}-F \tilde{h}$ on $Q^{N}$ and so on $U^{N}$. Since the extensions thus coincide, we have a well-defined map $T: H^{\infty}(E) \rightarrow H^{\infty}\left(U^{N}\right)$ such that $\|T(g)\|_{U^{N}} \leqq \gamma\|g\|_{E}$.

To see that $T$ is linear, let $g$ and $\widetilde{g}$ be bounded holomorphic functions on $E$ and let $\lambda$ be a complex number. Let $G$ and $\widetilde{G}$ respectively be arbitrary holomorphic extensions to $U^{N}$. Let $\widetilde{\widetilde{h}}, h_{1}, \widetilde{h}_{1}$ and $\widetilde{\widetilde{h}}, h, \widetilde{h}$ be the $h_{1}$ and the $h$ for $G+\lambda \widetilde{G}, G$ and $\widetilde{G}$ respectively. Then

$$
\begin{aligned}
\widetilde{\tilde{h}}_{1} & =\frac{1}{2 \pi i} \int \frac{(G+\lambda \widetilde{G}) / F}{\zeta-z_{1}} d \zeta \\
& =\frac{1}{2 \pi i} \int \frac{G / F}{\zeta-z_{1}} d \zeta+\lambda \cdot \frac{1}{2 \pi i} \int \frac{\widetilde{G}}{\zeta-z_{1}} d \zeta=h_{1}+\lambda \widetilde{h}_{1}
\end{aligned}
$$

and $\widetilde{\widetilde{h}}=\Pi\left(1-\pi_{j}\right) \widetilde{h}_{1}=\left[\Pi\left(1-\pi_{j}\right)\right]\left(h_{1}+\lambda \widetilde{h}_{1}\right)=h+\lambda \widetilde{h}$. Therefore

$$
\begin{aligned}
T(g+\lambda \widetilde{g}) & =(G+\lambda \widetilde{G})-F(h+\lambda \widetilde{h}) \\
& =(G-F h)+\lambda(\widetilde{G}-F \widetilde{h})=T(g)+\lambda T(\widetilde{g}) .
\end{aligned}
$$

ExAmple. Let $\mathrm{E}$ be the Rudin variety in $U^{2}$ given by $E=$ $Z\left(\left(z_{2}-\frac{1}{2}\right)\left(z_{1} z_{2}-\frac{1}{2}\right)\right)$. Then $E$ is the disjoint union of $Z\left(z_{2}-\frac{1}{2}\right)$ and $Z\left(z_{1} z_{2}-\frac{1}{2}\right)$. Let $g \in H^{\infty}(E)$ be given by

$$
g \mid Z\left(\left(z_{2}-\frac{1}{2}\right)=0 \text { and } g \mid Z\left(z_{1} z_{2}-\frac{1}{2}\right)=1 .\right.
$$


Then $g$ admits no bounded holomorphic extension to $U^{2}$. For if $G$ were a bounded extension of $g$ to $U^{2}$ we would have for $z \in U, z$ near 1 ,

$$
\begin{aligned}
1= & G\left(z, \frac{1}{2 z}\right)-G\left(z, \frac{1}{2}\right)=\frac{1}{2 \pi i} \int_{|\zeta|=1} G(z, \zeta)\left(\frac{1}{\zeta-\frac{1}{2 z}}-\frac{1}{\zeta-\frac{1}{2}}\right) d \zeta \\
& =\left(\frac{1}{2 z}-\frac{1}{2}\right) \frac{1}{2 \pi i} \int_{|\zeta|=1} \frac{G(z, \zeta)}{\left(\zeta-\frac{1}{2 z}\right)\left(\zeta-\frac{1}{2}\right)} d \zeta .
\end{aligned}
$$

But as $z \rightarrow 1$, the integral is bounded and $(1 / 2 z)-(1 / 2) \rightarrow 0$, a contradiction.

\section{REFERENCES}

1. Robert C. Gunning and Hugo Rossi, Analytic functions of several complex variables, Prentice-Hall, Englewood Cliffs, New Jersey, 1965.

2. Walter Rudin, Zero-sets in polydiscs, Bull. Amer. Math. Soc. 73 (1967), 580-583.

Received January 8, 1968. The research for this paper war partially supported by the following contracts: NONR 222 (85) and NONR 3656 (08).

UNIVERSITY OF MICHIGAN 


\section{PACIFIC JOURNAL OF MATHEMATICS}

\section{EDITORS}

H. ROYDEN

Stanford University

Stanford, California

\author{
R. R. Phelps \\ University of Washington \\ Seattle, Washington 98105
}

J. DugundJI

Department of Mathematics

University of Southern California

Los Angeles, California 90007

RICHARD ARENS

University of California

Los Angeles, California 90024

\section{ASSOCIATE EDITORS}

E. F. BECKenbaCH

B. H. NEUMANN

F. WOLF

K. YoSHIDA

\section{SUPPORTING INSTITUTIONS}

\author{
UNIVERSITY OF BRITISH COLUMBIA \\ CALIFORNIA INSTITUTE OF TECHNOLOGY \\ UNIVERSITY OF CALIFORNIA \\ MONTANA STATE UNIVERSITY \\ UNIVERSITY OF NEVADA \\ NEW MEXICO STATE UNIVERSITY \\ OREGON STATE UNIVERSITY \\ UNIVERSITY OF OREGON \\ OSAKA UNIVERSITY \\ UNIVERSITY OF SOUTHERN CALIFORNIA
}

\author{
STANFORD UNIVERSITY \\ UNIVERSITY OF TOKYO \\ UNIVERSITY OF UTAH \\ WASHINGTON STATE UNIVERSITY \\ UNIVERSITY OF WASHINGTON \\ $\stackrel{*}{*} \stackrel{*}{*} \stackrel{*}{*}$ AMERICAN MATHEMATICAL SOCIETY \\ CHEVRON RESEARCH CORPORATION \\ TRW SYSTEMS \\ NAVAL WEAPONS CENTER
}

The Supporting Institutions listed above contribute to the cost of publication of this Journal, but they are not owners or publishers and have no responsibility for its content or policies.

Mathematical papers intended for publication in the Pacific Journal of Mathematics should be in typed form or offset-reproduced, double spaced with large margins. Underline Greek letters in red, German in green, and script in blue. The first paragraph or two must be capable of being used separately as a synopsis of the entire paper. It should not contain references to the bibliography. Manuscripts, in duplicate if possible, may be sent to any one of the four editors. Please classify according to the scheme of Math. Rev. 36, 1539-1546. All other communications to the editors should be addressed to the managing editor, Richard Arens, University of California, Los Angeles, California, 90024.

50 reprints are provided free for each article; additional copies may be obtained at cost in multiples of 50 .

The Pacific Journal of Mathematics is published monthly. Effective with Volume 16 the price per volume (3 numbers) is $\$ 8.00$; single issues, $\$ 3.00$. Special price for current issues to individual faculty members of supporting institutions and to individual members of the American Mathematical Society: $\$ 4.00$ per volume; single issues $\$ 1.50$. Back numbers are available.

Subscriptions, orders for back numbers, and changes of address should be sent to Pacific Journal of Mathematics, 103 Highland Boulevard, Berkeley, California, 94708.

PUBLISHED BY PACIFIC JOURNAL OF MATHEMATICS, A NON-PROFIT CORPORATION

Printed at Kokusai Bunken Insatsusha (International Academic Printing Co., Ltd.), 7-17, Fujimi 2-chome, Chiyoda-ku, Tokyo, Japan. 


\section{Pacific Journal of Mathematics \\ Vol. 29, No. $3 \quad$ July, 1969}

Herbert James Alexander, Extending bounded holomorphic functions from certain subvarieties of a polydisc ...................... 485

Edward T. Cline, On an embedding property of generalized Carter

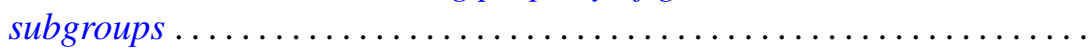

Roger Cuppens, On the decomposition of infinitely divisible characteristic functions with continuous Poisson spectrum. II ...............

William Richard Emerson, Translation kernels on discrete Abelian

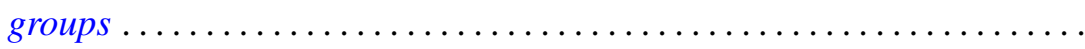

Robert William Gilmer, Jr., Power series rings over a Krull domain ....... 543

Julien O. Hennefeld, The Arens products and an imbedding theorem ...... 551

James Secord Howland, Embedded eigenvalues and virtual poles ........ 565

Bruce Ansgar Jensen, Infinite semigroups whose non-trivial homomorphs are all isomorphic .............................. 583

Michael Joseph Kascic, Jr., Polynomials in linear relations. II .......... 593

J. Gopala Krishna, Maximum term of a power series in one and several

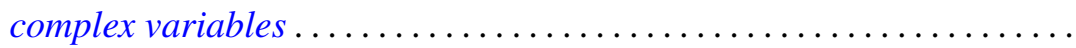

Renu Chakravarti Laskar, Eigenvalues of the adjacency matrix of cubic lattice graphs ...................................

Thomas Anthony Mc Cullough, Rational approximation on certain plane

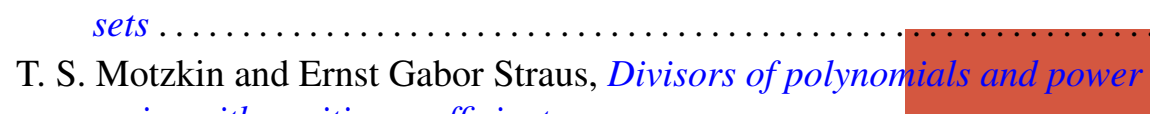
series with positive coefficients .

Graciano de Oliveira, Matrices with prescribed characteristic polynomial and a prescribed submatrix.

Graciano de Oliveira, Matrices with prescribed characteristic polynomial and a prescribed submatrix. II .

Donald Steven Passman, Exceptional 3/2-transitive permutation groups .................................

Grigorios Tsagas, A special deformation of the metric with no negative sectional curvature of a Riemannian space............

Joseph Zaks, Trivially extending decompositions of $E^{n}$ 